\title{
A Study of Mitotic Index in Differentiating Central Nervous System of Chick
}

\author{
J. Medda and A. Bose \\ Zoology Department, Kalyani University, Kalyani, \\ Nadia, W. B., India
}

Received December 6, 1967

The development of the nervous system of chick is associated with the emergence of the cytoarchitectural features that form its scaffolding. The nervous system of the bird passes through some basic epigenetic processes as cellular proliferation, differentiation and migration when two major cell types viz. the neurons (the functional cells of the nervous system) and supporting elements (ependymal, neuroglial, sheath and capsular cells) are established (Romanoff 1960). Thus in the several strata of the neural tube initially composed of a single layer of the columnar epithelial cells (Duncan 1957), three zones can be identified:

(a) an innermost ependymal zone of the neural germinal epithelium surrounded by

(b) the mantle zone composed of undifferentiated cells and (c) the peripheral or marginal zone within which the white substance develops.

Though adult nerve cells seldom divide (Weiss 1958, Bertalanffy and Lau 1963) cell proliferation occurs at the early stage of neural differentiation (Kallen 1965) and the ventricular neural epithelal cells in the active mitotic phase are regarded as 'germinal' ones (Hamburger 1948, Corliss and Robertson 1963, Watterson 1965) at least after the establishment of the mantle zone. In recent years, a number of studies on avian and mammalian embryos has indicated that mitotic figures in the neural tube always occur near the lumen (Mckeehan 1966) though there is a migration of the epithelial nuclei to and from the lumen during a complete mitotic cycle (Watterson et al. 1956, Sauer and Walker 1959, Fujita 1963, Martin and Langman 1965). The present investigation concerns with the survey with the mitotic index in the following four principal zones; the fore-, mid-, hind-brain and the spinal cord of chick, at different stages of development. Quantitative data are obtained on the potency of cell proliferation in these four sectors of the central nervous system of chick which may be useful to understand the problem of differentiation of the neurons.

\section{Material and methods}

The study is based on white leghorn chick embryos incubated at a constant temperature of $38^{\circ} \mathrm{C}$. The central nervous system of the embryos at different ages were dissected out and fixed in alcoholic Bouin's or San Falice fixatives. After routine process of embedding in paraffin, serial sections were made at $10 \mu$ and stained in Heidenhain's haematoxylin. Mitotic indices were ascertained by considering the dividing and the nondividing cells in the tissues (Bertalanffy and Lau 1963). Countings of cells were followed by the method of Mckeehans (1951) by taking nine areas, $0.105 \mathrm{~mm}^{2}$ each, in each of the three zones viz. ependyma, mantle and periphery around the neurocoele (Fig. 1). In the early stage of development, when these three zones renain very thin, the entire cell population was taken into consideration. Alternate sections were followed in order to avoid duplication in countings. Mitotic indices were recorded in the cerebrum (fore-brain), optic lobes (mid-brain), cerebellum (hind-brain) and the spinal cord of the same embryo. At least five embryos of every stage of development were studied. As it is known that, contrary to the results found in the amphibian larvae (Shell 1961), treatment of embryos with colchicine 


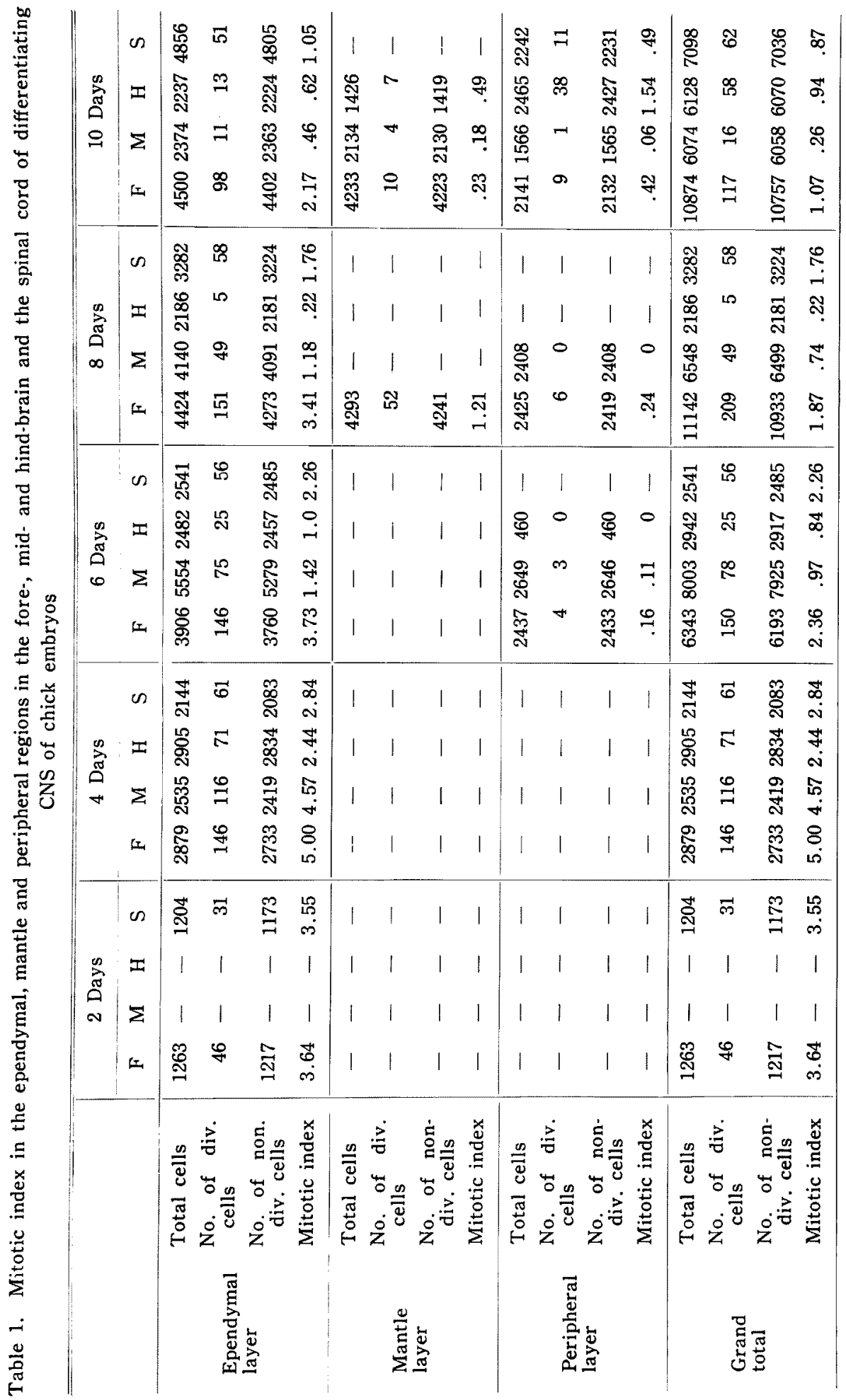




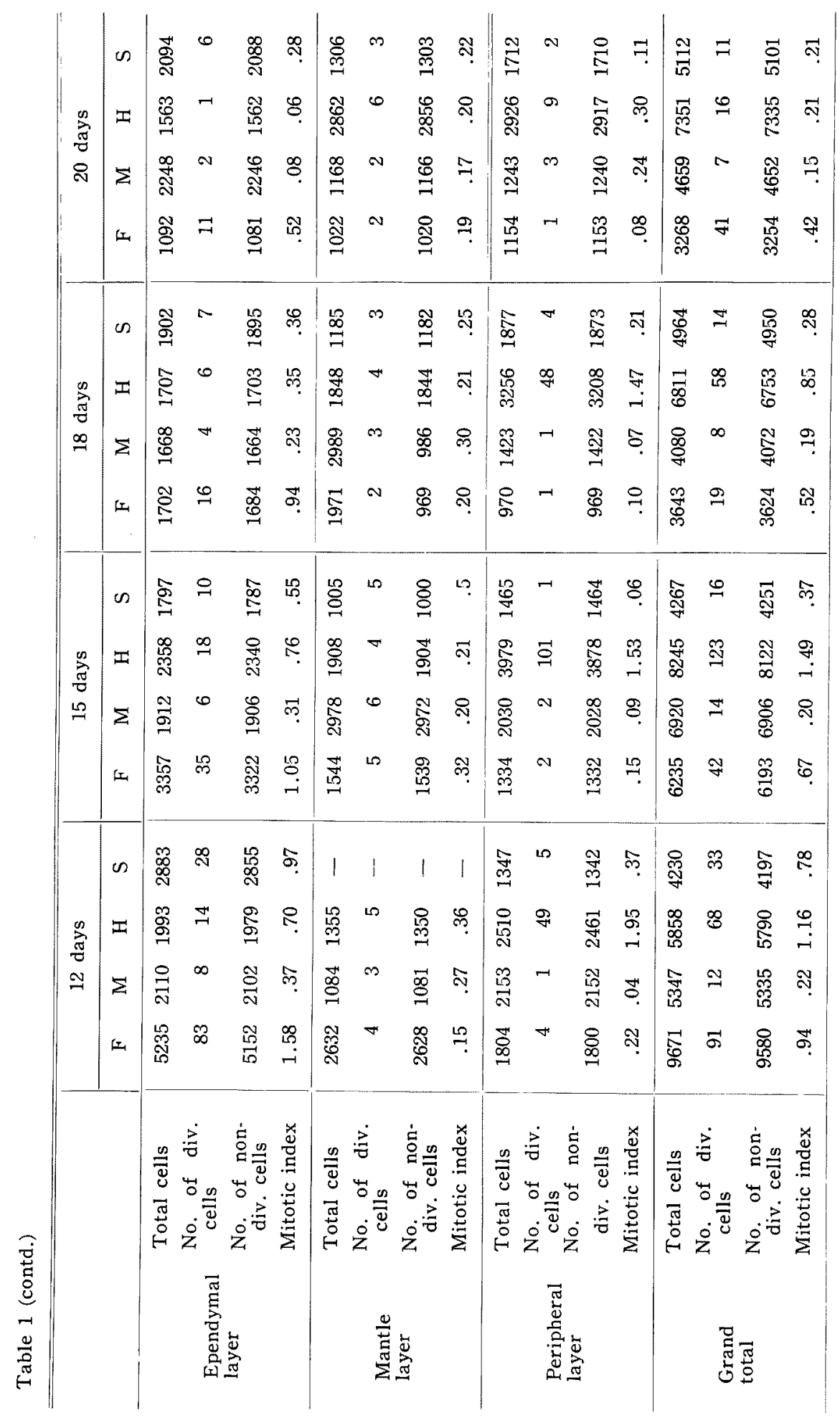


of varied concentrations for different periods develop some abnormalities (Overton 1958, Watterson 1965), normal untreated embryos have been considered in this study.

\section{Observations}

The different aspects of the study viz. cell number, dividing cells, nondividing cells, mitotic index at different stages of the embryos have been shown in Table 1.

It may be observed that mitotic indices in the brain and in the spinal cord of the 48 hours' embryos are nearly equal viz. 3.64 in the brain and 3.55 in the spinal cord region. As the central nervous system is small and not properly differentiated, the border areas of the midand the hind-brain can not be distiguished. Moreover, owing to the slender nature, the three zones round the neurocoele can not be demarcated.

In the 4-day embryos, different sectors of the nervous system are formed though the three zones round the neurocoele can not be distinguished properly. At this stage, it

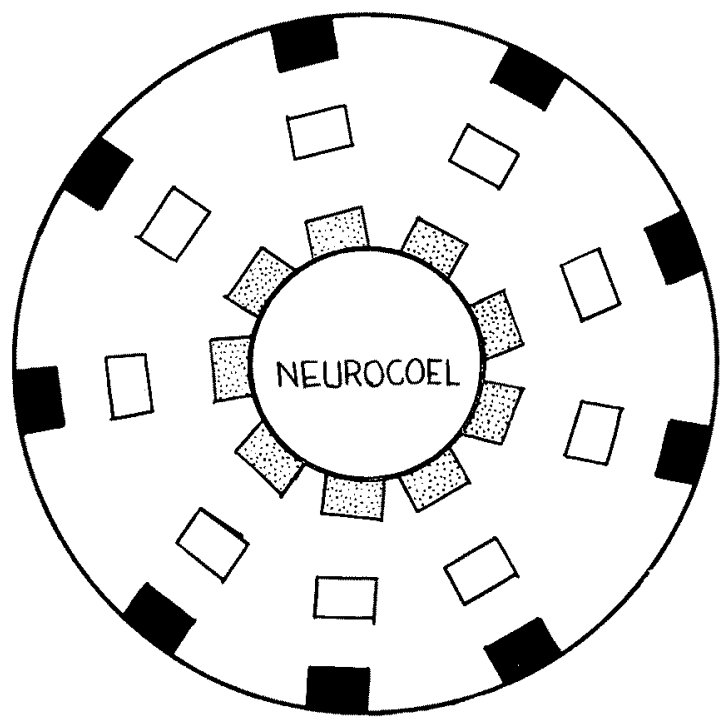

Fig. 1. Diagram of the field used in making cell counts in a cross section of the central nervous system. The rectangles show the approximate positions of samples for cell counts in the three zones of a section in the study.

may be observed that the mitotic index at the fore brain area increases to 5.00 while that of the spinal cord decreases to 2.84 . In the mid and in the hind brain regions these figures are 4.57 and 2.44 respectively. In the 6 - and in the 8-day embryos, the mitotic indices in all the four sectors fall from the corresponding figures of 4 -day embryos. Thus in the cerebrum mitotic indices are 3.73 and 3.41 while in the spinal cord, the related values are 2.26 and 1.76 respectively. Similarly in the mid and in the hind brain regions of the 6 -day embryos, mitotic indices are 1.42 and 1.00 respectively and the corresponding figures in the 8-day embryos are 1.18 and 0.22 
From 10-day onwards, the three zones viz. ependymal, mantle and peripheral in almost all the sectors become evident. In 10-day embryos, it may be observed that the mitotic index in the cerebral areas become further diminished to 2.17. In the mantle and in the peripheral areas the figures are 0.23 and 0.42 -the mitotic index in the peripheral area being slightly greater than that of the mantle area. In the optic lobes the mitotic index in the ependymal layer is 0.46 while those of the mantle and in the peripheral areas are 0.18 and 0.06 respectively. In the cerebellum, mitotic index is highest in the peripheral zone i.e. 1.54 as against 0.62 in the ependymal or 0.49 in the mantle area. The peripheral zone of the spinal cord shows a mitotic index of 0.49 against 1.05 of the ependymal layer. Here, the mantle area can not be demarcated properly.

Mitotic index becomes gradually decreased in the subsequent phases of development in the ependymal layer of cerebrum e.g. it is 1.58 and in 12-day embryos the value becomes 0.52 in 20 -day embryos. In the mantle areas of the cerebrum there is a slight increase in the mitotic index in the 15-day embryos after which it is decreased while in the peripheral zone mitotic index shows gradual downward trend.

A more or less similar picture is observed in the ependymal and mantle layer of the midbrain except in the 18-day embryos where a slight increase in the mitotic index in the mantle area is recorded. But at 20 days' incubation it goes down again. It may be seen in the peripheral area that the mitotic index does not follow a straight line curve and at 20 days' incubation there is much increase in the magnitude viz. 0.24 from 0.07 of 18 -day embryos. The spinal cord shows a similar decline in the mitotic index as that of the cerebral area, the slight alteration of the curve being at the peripheral zone of 18-day embryos when there is a small increase in the mitotic index. In the cerebellum, the curve for the mitotic index in the ependymal layer shows a decline upto 8-days of incubation but subsequently it increases upto 15 days. In the mantle zone, the mitotic index gradually decreases while there is remarkable increase in its magnitude in the peripheral zone of the 10 to 15-day embryos. There is again a drop in the mitotic index in the subsequent days of development.

\section{Discussion}

In chick, the central nervous system is laid down as a results of induction by the primitive streak. It is known that the anterior part of the streak which is a strong organizer induces the brain (archencephalic induction) while the posterior part of the streak gives rise the spinal cord (spino caudal induction) (Waddington 1956). The cell types incorporated in the different sectors of the central nervous system are not physiologically equipotent (Brachet 1960). From the present survey of the mitotic indices it is revealed that the cells do not divide at equal proportion through the nervous system. 
Thus it may be observed that in the embryos of 48 hours of incubation i.e. immediately after the termination of the primary organizer action, the mitotic index of the brain and that of the spinal cord are nearly equal. But later in the forebrain, the mitotic index exceeds that of the spinal cord area. In case of chick, the formative phase of the brain begins with differentiation of the medullary plate and extends through the fourth and fifth day of incubation (Romanoff 1960) when mitotic index as seen from the study is the highest in all the sectors of the brain and in spinal cord region (Fig. 2). The second

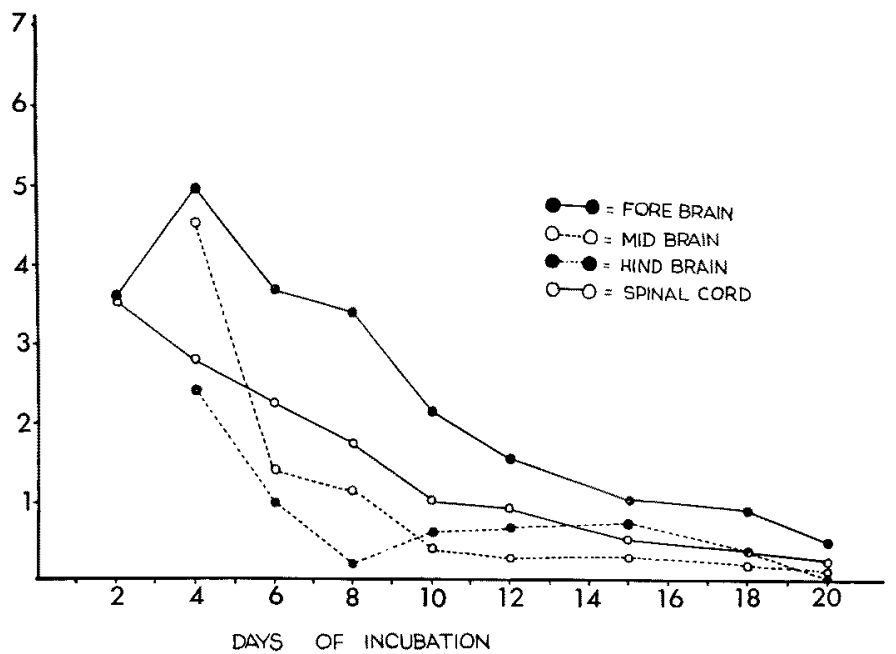

Fig. 2. Mitotic index in the ependymal in the differentiating central nervous system of chick.

phase of the development of the brain starting on the 5th or 6th day concerns with the structural modifications with differentiation of the nervous elements along with nerve centres and tracts. The definite cytoarchitecture of the central nervous system is attained by about 12th day of incubation. This process as revealed from the present survey is associated with a gradual fall in the mitotic indices and in the proliferating phase of the germ cells from the ependyma. But this decline is not uniform in all the sectors as the cells in the mid- and hind-brain lose the proliferating property on the 6th day but those in the cerebral area retain this potency upto the 12 th day and in the spinal cord upto the 8th day of incubation. A tissue, according to Price (1958), should be regarded as growing when its mitotic index (i.e. percentage of dividing to nondividing cells at the same period) exceeds 1.5 . Hence, it may be said that growth and differentiation of the chick brain nearly reaching completion at 12 days of incubation are always associated with varied proliferating phase of cells at different stages of incubation indicating an unequal differentiating kinetics in the central nervous system. So far as the mitotic indices of the mantle and the peripheral zones are concerned it is observed that the mantle zone with a mitotic index always below 1.5 level, never shows a proliferating property. The cells of this region migrating from the germinal layer (Hamburger 1948) remain undifferentiated initially to be transformed into neural elements (Romanoff 1960). But the occasional increase in mitotic indiices in this zone may be due to the mesenchyme cells that migrate 
in this area (Mckeehan 1966).

In connection with the mitotic index in the peripheral area, it may be noted that the cells which intrude from outside into these portions of the central nervous system undergo mitosis at a quite different rate; it never attains $1.5 \%$ mark in the fore-, mid-brain and in the spinal cord area while in the hind brain particularly at 10 to 15 days' development the mitotic index exceeds $1.5 \%$ mark and these undifferentiated cells are believed to be associated with the development of 'folia' in the cerebellum (Romanoff 1960). This process of mitotic activity in the peripheral region of the cerebellum, is accompanied with a simultaneous increase in the mitotic index of the ependymal zone. Considering the three areas together, it may be observed that the proliferating phase of the mid- and the hind-brain area is active upto

Table 2. Details of the calculation of Regression Coefficient and its test of significance

\begin{tabular}{|c|c|c|c|c|c|c|c|c|}
\hline & S.S.(Z) & S.S.(X) & S.P. $(Z X)$ & b & $\begin{array}{l}\text { Regres- } \\
\text { sion mean } \\
\text { square }\end{array}$ & $\begin{array}{l}\text { Error } \\
\text { mean } \\
\text { square }\end{array}$ & $\begin{array}{c}\text { Calculated } \\
\mathrm{f} \text { value }\end{array}$ & Remark \\
\hline $\begin{array}{l}\text { Fore- } \\
\text { brain }\end{array}$ & 4.7277 & 310.1429 & -37.9161 & -0.1223 & 4.6371 & 0.0129 & $\begin{array}{c}359.46 \\
\text { for } 1 \& \& \\
7 \text { d.f. }\end{array}$ & $\begin{array}{l}\text { highly } \\
\text { signifi- } \\
\text { cant }\end{array}$ \\
\hline $\begin{array}{l}\text { Mid- } \\
\text { brain }\end{array}$ & 10.9548 & 227.875 & -47.7501 & -0.2086 & 9.9606 & 0.1657 & $\begin{array}{l}60.11 \\
\text { for } 1 \& \\
6 \text { d.f. }\end{array}$ & do \\
\hline $\begin{array}{l}\text { Hind- } \\
\text { brain }\end{array}$ & 8.6378 & 227.875 & -31.9672 & -0.1402 & 4.4818 & 0.6927 & $\begin{array}{l}6.47 \\
\text { for } 1 \& \\
6 \text { d.f. }\end{array}$ & do \\
\hline $\begin{array}{l}\text { Spinal } \\
\text { cord }\end{array}$ & 6.6295 & 310.1429 & -45.1982 & -0.1456 & 6.5808 & 0.0070 & $\begin{array}{c}940.11 \\
\text { for } 1 \& \\
7 \text { d.f. }\end{array}$ & do \\
\hline
\end{tabular}

S.S. $(Z)=$ Sum of square of $Z$ when $Z=\log _{e} Y$ and $Y=$ measurement of mitotic index in the ependymal layer.

S.S. $(X)=$ Sum of square of $X$ where $X$ is the number of days.

S.P. $(Z X)=$ Sum of product of $Z$ and $X$.

$\mathrm{b}=$ the regression coefficient.

4 days of incubation while in case of the forebrain and the spinal cord, it may extend upto 8 days. It may be argued that the proliferating processes in the central nervous systen in chick considered together is not governed by a simple cephalocaudal gradient and the mitotic behaviour in each region is different from the other as stated by Frieova and Jelinek (1963) that each part of the central nervous system of chick exhibits its own characteristics in mitotic behaviour. But if the ependymal zone is considered as the 'germinal' area in all the sectors of the central nervous system (Hamburger 1948, Corliss and Robertson 1963, Watterson 1965), it may be observed that measuring mitotic index in the $\log$ scale, the regression of $\log$ (mitotic index) is linear. The estimated regression coefficients in the ependymal area (Table 2) are (a) -0.1223 (fore-brain) (b) -0.2086 (mid-brain) (c) -0.1402 (hind-brain) and (d) -0.1456 (spinal cord). From analysis variance it is found that all regres- 
sions are highly significant.

\section{Summary}

1. Mitotic indices in the four principal sectors of the developing central nervous system in chick have been studied.

2. It is found that initially the brain and the spinal cord have more or less similar mitotic indices. Later varied mitotic indices are observed in the different sectors of the central nervous system.

3. The ependymal layer shows the proliferating property with a mitotic index reaching 1.5 level, but the mantle and the peripheral zones never show the proliferating nature, except the peripheral zone of the hind-brain.

4. The proliferating property of the ependymal layer gradually becomes diminished with a highly significant regression value.

5. The implications of the observations have been discussed.

\section{Literature cited}

Bertalanffy F. D. and Lau, C. 1963. Cell renewal in Int. Rev. Cytol. Acad. Press N. Y. 13: $357-366$.

Brachet, J. 1960. Biochemistry of Development. Pergamon Fress, N. Y.

Corliss, C. E. and Robertson, C. G. 1963 . The pattern of mitotic density in the early chick neural epithelium. J. Expt. Zool. 153(2): 125-140.

Duncan, D. 1957. Electron microscope study of the embryonic neural tube and notochord. Texas. Reports. Biol. Med. 115(1): 367-377.

Frieov, Z. and Jelinek, R. 1963. Cellular proliferation in the central nervous system of chick embryos III. Mitotic activities in the cephalic pouches from 2 nd to 6 th day of incubation. Cs. Morphologic. 11: 229-236.

Fujita, S. 1963. The matrix cells and cytogenesis in the developing central nervous system. J. Comp. Neur. 120: 37-42.

Hamburger, V. 1948. The mitotic pattern in the spinal cord of the chick embryo and their relation to the histogenetic process. J. Comp. Neur. 88: 221-284.

Kallen, B. 1965. Early morphogenesis and pattern formation in the central nervous system. Ed. R. L. DeHaan and H. Ursprung. Holt, Rinehart and Winston. N. Y.: 107-128.

Martin, A. and Langman, J. 1965. The development of the spinal cord examined by autoradiography. J. Embryol. exp. Morph. 14: 25-35.

Mckeehan, M. S. 1951. Cytological aspects of embryonic lens induction in chick. J. Expt. Zool. 117(1): 31-64.

- 1966. The mitotic pattern in the neural tube of A. maculatum. Anat. Rec. 154: 705712.

Overton, J. 1958. Effects of colchicine on early chick blastoderm. J. Exptl. Zool. 139: 329-347.

Price, D. 1958. in Dynamics of Proliferating Tissue. Ed. E. Price. The Univ. of Chicago Press. P. 11.

Romanoff, A. L. 1960. The Avian Embryos. McMillan Press. N. Y.

Sauer, M. E. and Walker, B. E. 1959. Radioautographic study of interkinetic neuclear migration in the neural tube. Proc. Soc. Exp. Biol. Med. 101: 557-560.

Shell, L. S. 1961. Comparison of mitotic figures distribution in the central nervous system of normal and colchicine treated $R$. pipiens embryos. Am. Zool. 1(3): 131.

Waddington, C. H. 1956. Principles of Embryology. Gorge Allen and Co. Edin. 
Watterson, R. L., Veneziano, P. and Bertha, A. 1956. Absence of a true germinal zone in neural tubes of young chick embryos as demonstrated by colchicine technique. Anat. Rec. 124: 379.

- 1965. Structure and mitotic behaviour of the early neural tube in Organogenesis. Ed. R. L. DeHaan and H. Ursprung. Holt, Rinehart and Wingston, N. Y. P.: 129-159.

Weiss, P. 1958. in Dynamics of Proliferating Tissue. Ed. D. Price. The Univ. of Chicago Press. P. 3. 